\title{
Combination of exchange transfusion treatment and hydroxyurea cause beneficial changes to laboratory parameters and clinical outcome in patients with sickle cell disease/ $\beta$ thalassemia compared with hydroxyurea or exchange transfusion alone
}

\begin{abstract}
Sickle-cell disease is one of the most common severe monogenic disorders in the world. Hemoglobin polymerization, leading to erythrocyte rigidity and vaso-occlusion, is central to the pathophysiology of this disease, although the importance of chronic anaemia, haemolysis, and vasculopathy has been established. Clinical management is basic and few treatments have been established in evidence base. Hydroxyurea (HU) is considered to be the most successful drug therapy for severe sickle cell disease (SCD). Red blood cell transfusion therapy also has significantly improved the morbidity and mortality of patients with SCD and improves the quality of life among these patients. This study favored chronic transfusions and hydroxyurea compared with hydroxyurea alone or red cell exchange for the outcomes: annual crisis rate; acute chest syndrome; stroke; anemia; pulmonary hypertension; liver function. Levels of hemoglobin, fetal hemoglobin and hemoglobin S; MCV; No serious adverse effects were reported from the study. We conclude that chronic transfusions combinated with hydroxyurea improve the quality of life and the laboratory parameters in adults with SCD without any adverse effects over the last 5years.
\end{abstract}

Volume 2 Issue 4 - 2016

\author{
Sophia Delicou,' Maria Lavda,' Vlachopoulou \\ Argiri, ${ }^{2}$ Xydaki Aikaterini,' Karagrigoriou \\ Maria, ${ }^{2}$ Pallanza Zoi, ${ }^{2}$ Maragkos \\ Konstantinos' \\ Thalassemia and Transfusion Unit, Greece \\ ${ }^{2}$ Hematology Laboratory, Greece
}

Correspondence: Sophia Delicou, Clinical Hematologist, Thalassemia and Transfusion Unit, Hippokratio General Hospital, I I 4 Vassilisis Sofias str. I I 527, Athens, Greece, Tel +30 2132088464, Email sophiadelicou@gmail.com

Received: May 30, 2016 | Published: July 13, 2016

Keywords: exchange transfusion, hydroxyurea, sickle cell, combination, hemoglobin

Abbreviations: SCD, sickle cell disease; CT, computed tomography; PME, partial manual exchange transfusion; NHLBI, national heart, lung, and blood institute; TIA, transient ischemic attack; SCIC, sickle cell intrahepatic cholestasis; RCT, randomized controlled trial; ACS, acute chest syndrome; CTT, chronic transfusion therapy; SWiTCH, stroke with transfusions changing to hydroxyurea; $\mathrm{PH}$, pulmonary hypertension; $\mathrm{PAH}$, pulmonary arterial hypertension; MPAP, mean pulmonary artery pressure; RHC, right heart catheterization

\section{Introduction}

Sickle cell disease is a multisystem disease associated with episodes of acute painful illness and progressive organ damage. ${ }^{1-3}$ The term sickle cell disease is used to refer to all the different genotypes that cause the characteristic painful clinical syndrome, such as homo zygosity for the $\beta$ s allele, and also the co-inheritance of the $\beta$ s and $\beta \mathrm{c}$ or the $\beta \mathrm{s}$ and the $\beta$-thalassemia allele. ${ }^{4}$ The high morbidity rate of SCD patients is related to vascular complications ${ }^{5}$ that include multiple chronic organ damage affecting the brain, heart, lungs, kidneys, liver, eyes, skin, and skeleton. Vaso-occlusive crises result in acute and chronic severe pain, as well as acute chest syndrome, splenic sequestration, hemolytic anemia, stroke, acute and chronic multi-system organ damage, and shortened life expectancy. Chronic transfusion $^{6}$ and hydroxyurea ${ }^{1}$ are commonly used preventive treatments for sickle cell disease. Transfusion therapy is the standard of care to prevent an increased risk of stroke reducing the frequency of pain and acute chest syndrome. Hydroxyurea is a drug that used to raise fetal hemoglobin and is an attractive to transfusion for clinical complications including chronic pain, ACS, stroke and hospitalizations.

\section{Patients and methods}

The study was conducted at Thalassemia and Transfusion Department of Hippokratio Athens Hospital. The medical records of 30patients who were in continuously follow up since 2010-2015 were retrospectively analyzed. The patients were identified who had clinical events for the use of hydroxyurea alone, exchange transfusion, or combination of chronic transfusion and hydroxyurea.

For each patient the steady state hematological parameters were obtained. SCD genotypes were established by hemoglobin analysis by HPLC (Variant II-HPLC, Board) methods. All patients were followed up every month with a complete blood count and differential, biochemistry and $\mathrm{HbS} / \mathrm{HbF}$ levels. All the important adverse effects and the reported events by the patients reviewed in every visit. Examinations were performed to evaluate cardiac function using pulsed two-dimensional $\mathrm{M}$ mode and color flow Doppler echocardiography. Cardiac dimensions and pulmonary parameters were measured according to the criteria of the American Society of Echocardiography. Chest Computed Tomography (CT) was performed with high resolution protocol to determine the diameter of pulmonary artery. Neurological evaluation and MRI /MRA were performed before the enrollment. 
In our patients hydroxyurea was started at a dose of $15 \mathrm{mg} / \mathrm{kg}$ per day in a single oral dose and the dose escalated every four weeks to the maximum tolerated dose or to a maximum dose of $30 \mathrm{mg} / \mathrm{kg}$ per day. Sickle cell disease patients were prescribed transfusions every $3-4$ weeks with the goal of maintaining $\mathrm{HbS}$ levels of $\leq 30 \%$, according to the standard clinical care guidelines of the National Heart, Lung, and Blood Institute (NHLBI). ${ }^{7}$ Transfusion modalities included either:

i. Simple transfusion (ST) of $10-15 \mathrm{~mL} / \mathrm{kg}$ RBCs with the posttransfusion $\mathrm{Hb}$ goal of $11.5-12.0 \mathrm{~g} / \mathrm{dL}$

ii. Partial manual exchange transfusion (PME): Removal of $5-10 \mathrm{~mL} / \mathrm{kg}$ of whole blood prior to transfusion of $10-15 \mathrm{~mL} /$ $\mathrm{kg} \mathrm{RBCs}$ with the post-transfusion $\mathrm{Hb}$ goal of $10-12.0 \mathrm{~g} / \mathrm{dL}$ or

iii. Automated RBC exchange ${ }^{1}$ with the post-transfusion goal of $25-30 \%$ fraction of cells remaining and $\mathrm{Hb}$ approximately $0-2 \mathrm{~g} / \mathrm{dL}$ above the pre-transfusion $\mathrm{Hb}$.

All RBC units were pre-storage leuko reduced, sickle-negative, $\mathrm{ABO} / \mathrm{Rh}$ compatible, $\mathrm{C} / \mathrm{c}, \mathrm{E} / \mathrm{e}$, and Kell matched with additional antigenic matching dependent on alloantibody identification. Regularly scheduled blood transfusion therapy or exchange transfusion involves periodic transfusion of the patient at regularly scheduled intervals, with the frequency guided by the patient's symptoms, Hgb, and percent $\mathrm{HgbS}$. A detailed deferoxamine or deferasirox protocol after 1 year of chronic transfusion therapy or exchange blood transfusion was initiated.

\section{Patient's characteristics}

30patients (15male, 15 female), with $\mathrm{S} / \mathrm{S}$ genotype $5 / 30$ and $\mathrm{S} / \beta$ genotype $25 / 30$ and mean age at the study entry 45 , 2years, were divided into three subgroups of 10 , depending on the received therapy: hydroxyurea, exchange blood transfusion, and exchange transfusion and hydroxyurea combination. The indications for entering in each subgroup were: more than 5 painful hospitalizations/year 10/30, ACS 6/30, prevention of stroke 8/30, pulmonary hypertension 4/30, symptomatic or severe anemia $1 / 30$ and liver disease $1 / 30$. Mean $\mathrm{HB}, \mathrm{HBS}, \mathrm{HBF}$ and $\mathrm{MCV}$ were calculated in all groups, pre and post treatment. Mean difference of HB, HBS, HBF and MCV from baseline to post treatment were also calculated, in all groups (Pre treatment value-Post treatment value).
For the statistical analysis continuous variables are presented as mean \pm 1 standard deviation unless stated otherwise. The nonparametric Shapiro-Wilk test and histograms were used to assess, statistically and graphically, the normality of distribution of continuous variables. Between-groups differences were evaluated by two-tailed, independent samples Student's t-test or Wilcoxon non-parametric test when appropriate. One-way ANOVA was used to compare means among the groups. ANOVA repeated measurements were used to calculate the mean differences of HB, HBS, HBF and MCV at pretreatment stage and post-treatment stage. Post-hoc analysis was performed using the Bonferroni correction. Although all distribution were approached by normal distribution, due to the small number of patients in every group we performed Kruskal Wallis test also. The level of significance that was considered was 0.05 . Statistical analysis was performed by IBM SPSS v.23.

To assess whether hydroxyurea or exchange transfusion or combination of hydroxyurea and transfusion was associated with decreased organ damage, we compared the incidence of clinical events and their connection with the laboratory parameters at the enrollment and at the end of the study. To compare the clinical significance we use a repeated-measures t-test (paired samples t-test). The result is significant at $\mathrm{p} \leq 0.05$ and 0.01 .

\section{Results}

Of the 30 patient who enrolled the study beginning in 2010,29/30 was alive with available laboratory and clinical data after initial follow-up. At last evaluation, 10 remain on hydroxyurea 9 receive exchange or single transfusions and 10 received combination therapy with hydroxyurea and exchange transfusions. The clinical data, demographics and results are at Table 1. In group 1 (hydroxyurea) of the $7 / 10$ patients who enrolled with painful crisis only $3 / 10$ had more than 5 painful crisis/year at the end of the study which is significant to treatment. Of the $2 / 10$ that enrolled with ACS only 1 relapsed and had a new episode of ACS. At the time of relapse this 56year old man had discontinued the treatment with hydroxyurea due to dysthymic disorder. He switched back to treatment with a dose of $30 \mathrm{mg} / \mathrm{kg} /$ day and there has been no further recurrence. Of $1 / 10$ patients who enrolled with stroke there was no relapse or a new event.

Table I Patient characteristics

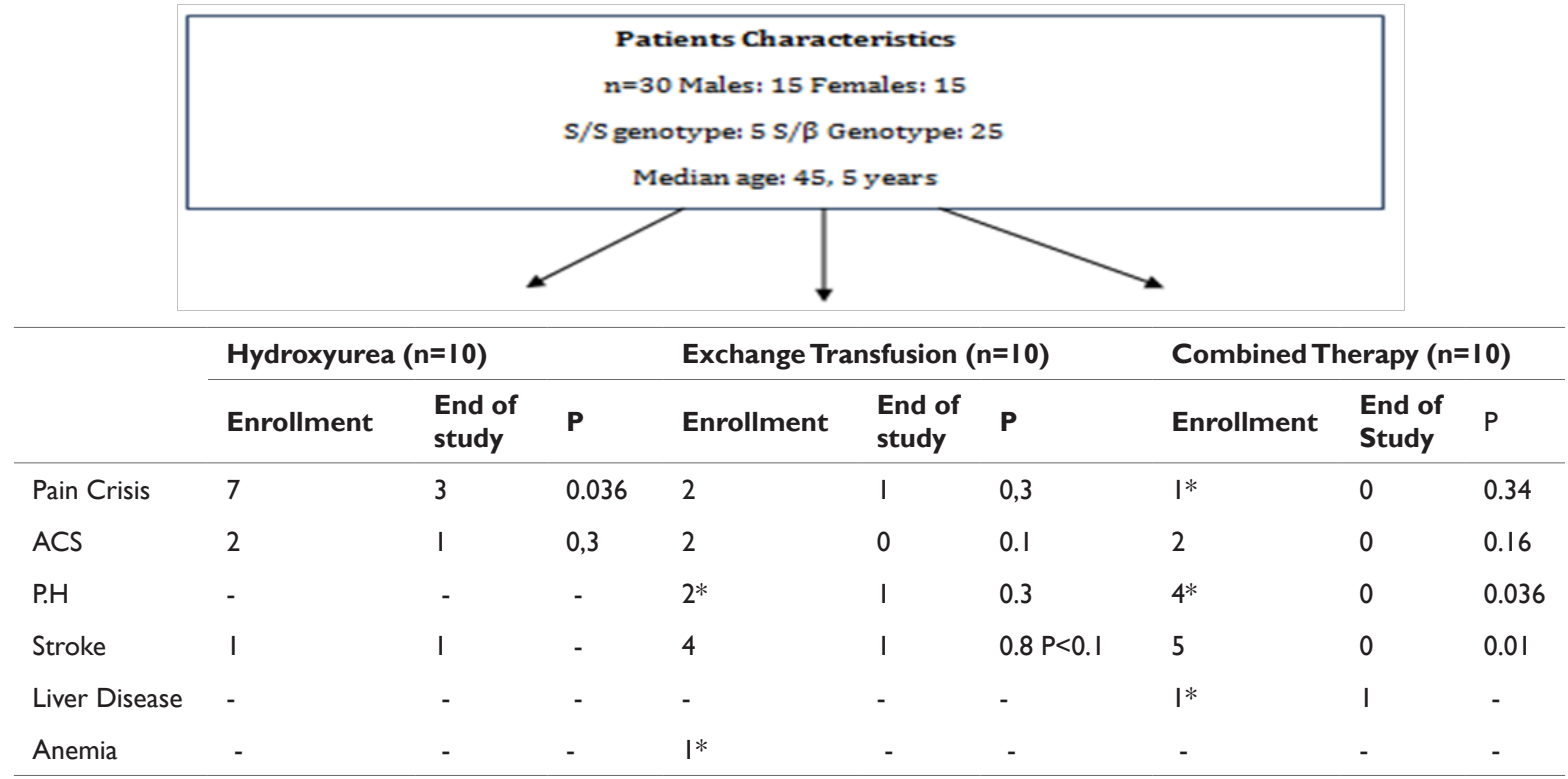

Citation: Delicou S, Lavda M,Argiri V, et al. Combination of exchange transfusion treatment and hydroxyurea cause beneficial changes to laboratory parameters and clinical outcome in patients with sickle cell disease/ $\beta$ thalassemia compared with hydroxyurea or exchange transfusion alone. Hematol Transfus Int J. 20I6;2(4):7I-75. DOI: I0.15406/htij.2016.02.00042 
In group 2 (exchange transfusion/transfusion) of the $2 / 10$ patients who enrolled with painful crisis, only $1 / 10$ had a more than 5 painful crisis during the study. This patient, a 50years old male, was under exchange transfusion program every 2-3 months while on transfusions had multiple auto- and allo-antibodies and there was a need of extended red cell phenotyping and difficulty finding compatible blood. Of the $2 / 10$ who enrolled with ACS none had a recurrent acute chest syndrome. The 4/10 patients with stroke who enrolled in exchange transfusion program one had experienced a new event of TIA presented with neurological deficits and negative MRA/ MRI. Of the 2/10 patients who enrolled in this group with pulmonary hypertension, the $1 / 2$ had a persistent hemodynamically significant pulmonary hypertension. This patient, a 76-year old woman had also abnormal kidney function which is an important parameter in patients with sickle cell disease and PH and has been related to mortality. The same patient had also a persistent anemia, underwent to exchange transfusion after she maintained the percent $\mathrm{HbS}$ near 30 and the pretransfusion Hct between 25-28\%.

In group 3 (combination of hydroxyurea and exchange transfusion) the $1 / 10$ patient who enrolled with debilitating painful crises, didn't experienced any painful crisis. Of the $2 / 10$ patient with ACS none had recurrent acute chest syndrome or developed chronic pulmonary disease. None of the $5 / 10$ had experienced a new event included transient ischemic attack (TIA) Both the 4/10 patients who enrollment with pulmonary hypertension, had a significant reduction in pulmonary artery pressure. The $1 / 10$ patient with liver disease, a 48 year old woman is the same with recurrent admissions for pain crisis and pulmonary hypertension sickle cell intrahepatic cholestasis (SCIC) has stayed stable with no evidence of impaired hepatic synthetic function, liver failure or portal hypertension and ascites.

HBS, HBF, HB and MCV pre and post treatment were compared and presented at Table 2 .In group 1, significant differences were observed at $\mathrm{HBS}, \mathrm{HBF}$ and $\mathrm{MCV}$ from baseline to post treatment stage. Similarly, in group 2 and 3, significant differences were observed at $\mathrm{HBS}, \mathrm{HBF}, \mathrm{MCV}$ and $\mathrm{HB}$ also from baseline to post treatment stage. When we compared the mean differences of HB, HBS, HBF and MCV (value at baseline value at post treatment stage) among the three groups, statistical differences was revealed. There was a significant decrease of HBS mostly in group 3(combination therapy) vs group 1 (hydroxyurea) and group 2 (blood transfusion) $(49.6 \pm 6.7 \%$ vs $9.2 \pm 2.8 \%$ and $35.3 \pm 7.4 \%$, respectively; $\mathrm{p}<0.001)$. A significant increase of HB was revealed in group 2 vs group $1(-1.97 \pm 0.79 \mathrm{mg} /$ dl vs $-0.02 \pm 0.31 \mathrm{mg} / \mathrm{dl}$, respectively; $\mathrm{p}<0.001$ ) but not vs group 3 $(-1.97 \pm 0.79 \mathrm{mg} / \mathrm{dl}$ vs $-1.48 \pm 0.85$, respectively; $\mathrm{p}=0.386)$ (Table2). Similarly, a significant increase of HBF was observed mostly in group 1 and group 3 vs a decrease in group $2(-8.40 \pm 3.41 \%$ and $-6.63 \pm 3.08$ $\%$ vs $0.77 \pm 0.77 \%$, respectively; $p<0.001)$. Finally, MCV increased significantly in group 1 and group 3 vs group $2(-21.30 \pm 3.26 \mathrm{FL}$ and $-24.50 \pm 5.16 \mathrm{FL}$ vs $-5.80 \pm 6.06 \mathrm{FL}$, respectively; $\mathrm{p}<0.001)$.

\section{Table 2}

\begin{tabular}{|c|c|c|c|c|c|c|c|c|c|c|c|c|}
\hline & \multicolumn{4}{|l|}{ Hydroxyurea } & \multicolumn{4}{|c|}{ Exchange transfusion/transfusion } & \multicolumn{4}{|l|}{ Combined } \\
\hline & Enrollment & $\begin{array}{l}\text { End of } \\
\text { study }\end{array}$ & $\mathbf{p}$ & $\begin{array}{l}\text { Mean } \\
\text { difference }\end{array}$ & Enrollment & $\begin{array}{l}\text { End of } \\
\text { study }\end{array}$ & $\mathbf{p}$ & $\begin{array}{l}\text { mean } \\
\text { difference }\end{array}$ & Enrollment & $\begin{array}{l}\text { End of } \\
\text { study }\end{array}$ & $\mathbf{p}$ & $\begin{array}{l}\text { Mean } \\
\text { difference }\end{array}$ \\
\hline $\begin{array}{l}\text { Hb } \\
\text { (mg/ } \\
\text { dl) }\end{array}$ & $9.06 \pm 0.91$ & $9.08 \pm 0.77$ & 0.844 & $-0.02 \pm 03 I^{\prime}$ & $8.47 \pm 1.39$ & $10.44 \pm 1.13$ & $<0.001$ & $-1.97 \pm 0.79^{\prime}$ & $9.51 \pm 1.28$ & $10.99 \pm 0.98$ & $<0.01$ & $-1.48 \pm 0.85^{2}$ \\
\hline $\begin{array}{l}\text { MCV } \\
\text { (fl) }\end{array}$ & $75.90 \pm 5.54$ & $97,2 \pm 7.08$ & 0.005 & $-21,3 \pm 3,26^{3}$ & $76.30 \pm 7.86$ & $82.10 \pm 3.84$ & 0.014 & $76.30 \pm 7.86^{3,4}$ & $76.90 \pm 5.68$ & $101.40 \pm 2.67$ & $<0.01$ & $-24.5 \pm 5.16^{4}$ \\
\hline $\begin{array}{l}\text { HbF } \\
\text { (\%) }\end{array}$ & $2.73 \pm 0.76$ & $11.1 \pm 3,42$ & $<0.01$ & $-8.40 \pm 3.4 I^{\prime}$ & $2.63 \pm 0.71$ & $1.86 \pm 0.57$ & 0.012 & $0.77 \pm 0.77^{1,4}$ & $1.92 \pm 0.37$ & $8.55 \pm 3.07$ & $<0.01$ & $-6.63 \pm 3.08^{4}$ \\
\hline $\begin{array}{l}\text { HbS } \\
\text { (\%) }\end{array}$ & $87.0 \pm 3.12$ & $77.8 \pm 5.5$ & $<0.01$ & $9.2 \pm 2.82^{1,2}$ & $84.10 \pm 3.54$ & $48.8 \pm 9.10$ & $<0.001$ & $35.50 \pm 7.43^{\prime}$ & $84.1 \pm 3.71$ & $34.8 \pm 5.05$ & $<0.01$ & $49.6 \pm 6.78^{2}$ \\
\hline
\end{tabular}

I. I-Indicates significant difference from group I to group 2 ( $p<0.00 \mathrm{I})$.

2. 2- Indicates significant difference from group I to group $3(p<0.00 I)$.

3. 3 -Indicates significant difference from group I to group 2 ( $p<0.00 \mathrm{I}$ ). 4-Indicates significant difference from group 2 to group 3 ( $p<0.00 \mathrm{I}$ ).

\section{Discussion}

Sickle cell disease is a life-long genetic disease that begins in childhood, affecting the structure of erythrocytes. ${ }^{2}$ Although SCA is genetically characterised by a single point mutation, there are various genetic modulators that affect the phenotype of this disease, and patients can manifest with varying degrees of clinical severity.,4 Recurrent episodes of acute, severe pain are the hallmark of SCD. ${ }^{8}$ The pain is highly variable both within and among patients, and is the result of complex and poorly understood interactions between biological and psychosocial factors. The association between painful VOC visits and hospitalizations and mortality as reported by the CSSCD almost 20 years ago still remains significant in the contemporary era of SCD specific therapies. ${ }^{5}$

Hydroxyurea (HU) was the first drug approved by the FDA for clinical use in sickle cell patients to induce $\mathrm{HbF}$ after its clinical effectiveness in reducing acute disease complications of painful crises and hospitalizations was demonstrated. ${ }^{1}$ However, clinical and laboratory response to $\mathrm{HU}$ is highly variable: not all patients reach a clinically significant increase in $\mathrm{HbF}$ even at maximum tolerated dose. Blood transfusion ${ }^{6}$ in SCD can serve two roles, either for therapy (typically for life-threatening SCD related complication) or for prophylaxis, to decrease the incidence of specific SCD related complications. Subsequently prospective studies have verified the efficacy and tolerability of hydroxyurea, leading to a placebocontrolled, randomized controlled trial (RCT) that demonstrated the efficacy of hydroxyurea in reducing painful vaso-occlusive crises and acute chest syndrome (ACS) in adults with SCA. Both children and adults with SCA benefited from reductions in the frequency of VOC in 11 studies. In our study, the use of hydroxyurea decreased significantly the painful crises. ${ }^{9-13}$ 
This is consistent with HBF's ability to inhibit HBS polymerization, thereby decreasing either vaso occlusion or hemolysis. Initial MCV suggesting that cells became more spherical during treatment, perhaps because cell surface area could not continue to increase as cell volume was expanded by increasing $\mathrm{Hb}$ content indicating that the increase in MCV was associated with proportionally increased cell water. ${ }^{14-16}$ Although, there are no randomized trials demonstrating the optimal treatment of acute chest syndrome in adults with sickle cell disease, transfusion therapy-especially exchange transfusion- has remained the cornerstone of management in moderate to severe cases of acute chest syndrome in several centers. In our study there was not significant difference between the three therapeutic groups. This could be due to the advances in medical care and management strategies over the past decade and reflects the impact of advances in medical care in the given time frame. ${ }^{17-20}$

Natural history studies reveal that nearly $70 \%$ of SCA patients will suffer a recurrent stroke if left untreated. Additionally, almost $40 \%$ of SCA patients who have an overt stroke also have evidence of vasculopathy on magnetic resonance angiography placing this group of patients at the highest risk for recurrent stroke. Moreover, $45 \%$ of SCA patients who have had an overt stroke will suffer progressive neurologic damage due to both overt and silent cerebral infarctions, despite chronic transfusion therapy (CTT). Hydroxyurea was not equivalent to transfusion in the Stroke with Transfusions Changing to Hydroxyurea (SWiTCH) trial based on a composite end point; in those patients who have experienced prior stroke or at risk of initial stroke based on elevated TCD velocity, chronic blood transfusion or exchange transfusion is the standard of care to prevent recurrence or initial stroke. In our study we found that patient at high risk for stroke had significantly improvement with combination therapy of Hydroxyurea and exchange transfusions, vs simple transfusions/ exchange transfusions vs hydroxyurea use. Subjects with the highest $\mathrm{MCV}$ values and $\mathrm{HbF}$ (group 3) had significantly more corroborative evidence of prevention from a new event of stroke..$^{21-28}$

A similar relationship has been described in sickle cell patients with pulmonary hypertension. Another one of the most controversial complications of sickle cell disease (SCD) is pulmonary hypertension $(\mathrm{PH})$. The words "pulmonary hypertension" like "anemia" does not indicate a specific diagnosis but imply a constellation of signs and symptoms that have many possible etiologies. The World Health Organization classifies PH into 5 groups which were collectively referred to as "pulmonary hypertension" with number one being pulmonary arterial hypertension (PAH). Pulmonary hypertension is defined as resting mean pulmonary artery pressure (MPAP) $\geq 25 \mathrm{mmHg}$ determined by right heart catheterization (RHC). Moreover, the hallmark of PAH, besides the elevated MPAP, is a coexistent pulmonary-capillary wedge pressure $\leq 15 \mathrm{mmHg}$. About $3 \%$ of patients with SS develop PAH and the overall prevalence of all types of PH in SS is approximately $6 \%$.

In both cases (Stroke and PH), exchange blood transfusion with hydroxyurea does more than simply raise the hemoglobin ( $\mathrm{Hgb})$ level for oxygen delivery; transfusion also lowers further the percentage of sickle Hgb (HgbS) and increases Hgb oxygen saturation, both of which decrease the propensity for vaso occlusion. The increased MCV may be linked to a reduce rate of sickling. The use of hydroxyurea is a mainstay in the overall management of individuals with SCD, since it reduces the incidence of hemolysis, and prolongs survival. ${ }^{29-33}$ The liver can be affected by a number of complications due to the disease itself and its treatment. In addition to the vascular complications from the sickling process, patients with SCD have often received multiple transfusions, placing them at risk for viral hepatitis, iron overload and (combined with the effects of chronic hemolysis) the development of pigment gallstones, all of which may contribute to the development of liver disease. In our study, the patient had multiorgan complications from the disease. ${ }^{34-36}$

\section{Conclusion}

Prompt and effective treatment for SCA and its complications is recommended as it is likely to improve survival. Further research is required to determine the etiology, pathophysiology and the most appropriate strategies for management of SCA. The results of this study showed the combination of chronic exchange transfusions and hydroxyurea is superior to hydroxyurea alone or chronic transfusions alone.

\section{Conflict of interest}

The authors certify that they have NO affiliations with or involvement in any organization or entity with any financial interest (such as honoraria; educational grants; participation in speakers' bureaus; membership, employment, consultancies, stock ownership, or other equity interest; and expert testimony or patentlicensing arrangements) or non-financial interest (such as personal or professional relationships, affiliations, knowledge or beliefs) in the subject matter or materials discussed in this manuscript.

\section{Acknowledgements}

Special thanks to my major advisors, Dr. Markisia Karageorgas and Prof. Athanassios Aessopos for their patience, understanding, guidance and most of all the encouragement they have given me during all this time. Sophia Delicou MD, Clinical Hematologist.

\section{References}

1. Brawley OW, Cornelius LJ, Edwards LR, et al. National institutes of health consensus development conference statement: hydroxyurea treatment for sickle cell disease. Ann Intern Med. 2008;148(12):932-938.

2. Platt OS. Hydroxyurea for the treatment of sickle cell anemia. $N$ Engl J Med. 2008;358(13):1362-1369.

3. Weatherall D, Akinyanju O, Fucharoen S, et al. Inherited disorders of hemoglobin. In: Jamison DT, et al. editors. Disease Control Priorities in Developing Countries. 2nd ed. Washington, USA: World bankl; 2006.

4. Rees DC, Williams TN, Gladwin MT. Sickle-cell disease. Lancet. 2010;376(9757):2018-2031.

5. Yale SH, Nagib N, Guthrie T. Approach to the vaso-occlusive crisis in adults with sickle cell disease. Am Fam Physician. 2000;61(5):13491356.

6. Wahl S, Quirolo KC. Current issues in blood transfusion for sickle cell disease. Curr Opin Pediatr. 2009;21(1):15-21.

7. Yawn BP, Buchanan GR, Afenyi-Annan AN, et al. Management of sickle cell disease: summary of the 2014 evidence-based report by expert panel members. JAMA. 2014;312(10):1033-1048

8. Rees DC, Olujohungbe AD, Parker NE, et al. Guidelines for the management of the acute painful crisis in sickle cell disease. $\mathrm{Br} J$ Haematol. 2003;120(5):744-752.

9. Vichinsky EP, Styles LA, Colangelo LH, et al. Acute chest syndrome in sickle cell disease: clinical presentation and course. Cooperative Study of Sickle Cell Disease. Blood. 1997;89(5):1787-1792. 
10. Stallworth JR, Jerrell JM, Tripathi A. Cost-effectiveness of hydroxyurea in reducing the frequency of pain episodes and hospitalization in pediatric sickle cell disease. Am J Hematol. 2010;85(10):795-797.

11. Lanzkron S, Haywood C, Hassell KL, et al. Provider barriers to hydroxyurea use in adults with sickle cell disease: a survey of the sickle cell disease adult provider network. J Natl Med Assoc. 2008;100(8):968973.

12. Steinberg $\mathrm{MH}$, Barton $\mathrm{F}$, Castro O, et al. Effect of hydroxyurea on mortality and morbidity in adult sickle cell anemia: risks and benefits up to 9 years of treatment. JAMA. 2003;289(13):1645-1651.

13. Strouse JJ, Lanzkron S, Beach $\mathrm{MC}$, et al. Hydroxyurea for sickle cell disease: a systematic review for efficacy and toxicity in children. Pediatrics. 2008;122(6):1332-1342.

14. Rodgers GP, Dover GJ, Uyesaka N, et al. Augmentation by erythropoietin of the fetal-hemoglobin response to hydroxyurea in sickle cell disease. $N$ Engl J Med. 1993;328(2):73-80.

15. Rodgers GP, Dover GJ, Noguchi CT, et al. Hematologic responses of patients with sickle cell disease to treatment with hydroxyurea. $N$ Engl J Med. 1990;322(15):1037-1045.

16. Noguchi CT, Rodgers GP, Serjeant G, et al. Levels of fetal hemoglobin necessary for treatment of sickle cell disease. $N$ Engl J Med. 1988;318(2):96-99.

17. Ferster A, Tahriri P, Vermylen C, et al. Five years of experience with hydroxyurea in children and young adults with sickle cell disease. Blood. 2001;97(11):3628-3632.

18. Siddiqui AK, Ahmed S. Pulmonary manifestations of sickle cell disease. Postgrad Med J. 2003;79(933):384-390.

19. Emre U, Miller ST, Gutierez M, et al. Effect of transfusion in acute chest syndrome of sickle cell disease. J Pediatr. 1995;127(6):901-904

20. Taylor C, Carter F, Poulose J, et al. Clinical presentation of acute chest syndrome in sickle cell disease. Postgrad Med J. 2004;80(944):346-349.

21. Swerdlow PS. Red cell exchange in sickle cell disease. Hematology Am Soc Hematol Educ Program. 2006. p. 48-53.

22. Scothorn DJ, Price C, Schwartz D, et al. Risk of recurrent stroke in children with sickle cell disease receiving blood transfusion therapy for at least five years after initial stroke. J Pediatr. 2002;140(3):348-354.

23. Gulbis B, Haberman D, Dufour D, et al. Hydroxyurea for sickle cell disease in children and for prevention of cerebrovascular events: the Belgian experience. Blood. 2005;105(7):2685-2690.
24. Hulbert ML, McKinstry RC, Lacey JL, et al. Silent cerebral infarcts occur despite regular blood transfusion therapy after first strokes in children with sickle cell disease. Blood. 2011;117(3):772-779.

25. Anderson R, Cassell M, Mullinax Gl, et al. Effect of normal cells on viscosity of sickle-cell blood: In vitro studies and report of six years' experience with a prophylactic program of partial exchange transfusion. Arch Intern Med. 1963;111(3):286-294.

26. Detterich JA, Sangkatumvong S, Kato R, et al. Patients with sickle cell anemia on simple chronic transfusion protocol show sex differences for hemodynamic and hematologic responses to transfusion. Transfusion 2003;53(5):1059-1068

27. Sakamoto TM, Canalli AA, Traina F, et al. Altered red cell and platele adhesion in hemolytic diseases: Hereditary spherocytosis, paroxysmal nocturnal hemoglobinuria and sickle cell disease. Clin Biochem. 2013;46(18):1798-1803

28. Ware RE, Schultz WH, Yovetich N, et al. Stroke With Transfusions Changing to Hydroxyurea (SWiTCH): a phase III randomized clinica trial for treatment of children with sickle cell anemia, stroke, and iron overload. Pediatr Blood Cancer. 2011;57(6):1011-1017.

29. De Castro LM, Jonassaint JC, Graham FL, et al. Pulmonary hypertension associated with sickle cell disease: clinical and laboratory endpoints and disease outcomes. Am J Hematol. 2008;3(1):19-25.

30. Parent F, Bachir D, Inamo J, et al. A hemodynamic study of pulmonary hypertension in sickle cell disease. $N$ Engl J Med. 2011;365(1):44-53.

31. Machado RF, Barst RJ, Yovetich NA, et al. Hospitalization for pain in patients with sickle cell disease treated with sildenafil for elevated TRV and low exercise capacity. Blood. 2011;118(4):855-864.

32. Gladwin MT, Sachdev V, Jison ML, et al. Pulmonary hypertension as a risk factor for death in patients with sickle cell disease. $N$ Engl J Med. 2004;350(9):886-895.

33. Machado RF, Gladwin MT. Chronic sickle cell lung disease: new insights into the diagnosis, pathogenesis and treatment of pulmonary hypertension. Br J Haematol. 2005;129(4):449-464.

34. Platt OS, Brambilla DJ, Rosse WF, et al. Mortality in sickle cell disease--life expectancy and risk factors for early death. $N$ Engl J Med. 1994;330(23):1639-1644.

35. Vichinsky EP. Current issues with blood transfusions in sickle cell disease. Semin Hematol. 2001;38(1 Suppl 1):14-22.

36. Zakaria N, Knisely A, Portmann B, et al. Acute sickle cell hepatopathy represents a potential contraindication for percutaneous liver biopsy. Blood. 2003;101(1):101-103. 